\title{
Deep seafloor arrivals: An unexplained set of arrivals in long-range ocean acoustic propagation
}

\author{
Ralph A. Stephen and S. Thompson Bolmer \\ Woods Hole Oceanographic Institution, Woods Hole, Massachusetts 02543-1542 \\ Matthew A. Dzieciuch and Peter F. Worcester \\ Scripps Institution of Oceanography, UCSD, La Jolla, California 92093-0225
}

Rex K. Andrew, Linda J. Buck, and James A. Mercer

University of Washington, Seattle, Washington 98105-6698

John A. Colosi

Naval Postgraduate School, Monterey, California 93943

Bruce M. Howe

University of Hawaii at Manoa, Honolulu, Hawaii 96822

(Received 5 November 2008; revised 12 May 2009; accepted 15 May 2009)

\begin{abstract}
Receptions, from a ship-suspended source (in the band $50-100 \mathrm{~Hz}$ ) to an ocean bottom seismometer (about $5000 \mathrm{~m}$ depth) and the deepest element on a vertical hydrophone array (about $750 \mathrm{~m}$ above the seafloor) that were acquired on the 2004 Long-Range Ocean Acoustic Propagation Experiment in the North Pacific Ocean, are described. The ranges varied from 50 to $3200 \mathrm{~km}$. In addition to predicted ocean acoustic arrivals and deep shadow zone arrivals (leaking below turning points), "deep seafloor arrivals," that are dominant on the seafloor geophone but are absent or very weak on the hydrophone array, are observed. These deep seafloor arrivals are an unexplained set of arrivals in ocean acoustics possibly associated with seafloor interface waves.
\end{abstract}

(C) 2009 Acoustical Society of America. [DOI: 10.1121/1.3158826]

PACS number(s): 43.30.Gv, 43.30.Re, 43.30.Nb, 43.30.Ma [RCG] Pages: 599-606

\section{INTRODUCTION}

The Long-Range Ocean Acoustic Propagation Experiment (LOAPEX) was carried out in the North Pacific Ocean between 10 September and 10 October 2004 (Mercer et al., 2005, 2009, 2006). Two goals of LOAPEX were to understand the role of bottom interaction in long-range, lowfrequency acoustic propagation, and to understand the physical mechanisms responsible for the so-called "deep shadow zone arrivals" observed by Dushaw et al. (1999). Deep shadow zone arrivals occur when acoustic energy is scattered vertically many wavelengths below a turning point (Van Uffelen et al., 2008, 2009, 2006) and examples will be shown below. The 2004 LOAPEX experiment was well suited to address these issues in three respects. First, broadband acoustic transmissions (in the band $50-100 \mathrm{~Hz}$ ) were simultaneously received on a pair of vertical hydrophone arrays spanning $3500 \mathrm{~m}$ of the water column and on four ocean bottom seismometer/hydrophones (OBS/Hs). The primary receiver was a deep vertical line array (DVLA) consisting of 60 hydrophones from nominal depths of 2150-4270 m (Worcester, 2005). A shallow vertical line array was deployed about $5 \mathrm{~km}$ west of the DVLA and consisted of 40 hydrophones at nominal depths from 350 to $1750 \mathrm{~m}$. The four $\mathrm{OBS} / \mathrm{Hs}$ rested on the seafloor and were located about $2 \mathrm{~km}$ west, north, east, and south of the DVLA. Second, the seven ship-suspended source locations varied from 50 to $3200 \mathrm{~km}$ from the DVLA (labeled T50, T250, etc.) so that the evolution of the shadow zone arrivals with range could be observed. Finally, at each source station signals were transmitted over intervals from 9 to $34 \mathrm{~h}$ so that the acoustic sensitivity to oceanic processes with time scales on the order of minutes to hours could be addressed.

\section{THE EXPERIMENT}

\section{A. Sources}

The acoustic source was suspended at depths of 350 , 500 , or $800 \mathrm{~m}$ and transmitted primarily phase-coded M-sequences [short for "binary maximal-length sequences" (Munk et al., 1995)] with a bandwidth from about 50 to $100 \mathrm{~Hz}$. Each M-sequence lasted approximately 30 seconds and sequential transmissions lasted for periods of 20 to $80 \mathrm{~min}$. The source parameters and transmission schedule are given in Mercer et al. (2009). For simplicity in this paper results are shown only for phase-coded $\mathrm{M}$-sequences with a $68.2 \mathrm{~Hz}$ carrier frequency and a 2 cycle per digit code modulation rate (henceforth referred to as M68.2 sequences) with the source at $350 \mathrm{~m}$ depth for ranges from 250 to $3200 \mathrm{~km}$ (only six combinations of source range, source depth, and transmission format from over 20 possible permutations) (Fig. 1 and Table I). Broadband source levels in this case were about $194 \mathrm{~dB}$ re $1 \mu \mathrm{Pa}$ at $1 \mathrm{~m}$ as derived from the sound pressure level measured at a monitoring hydrophone (Mercer et al., 2005). 


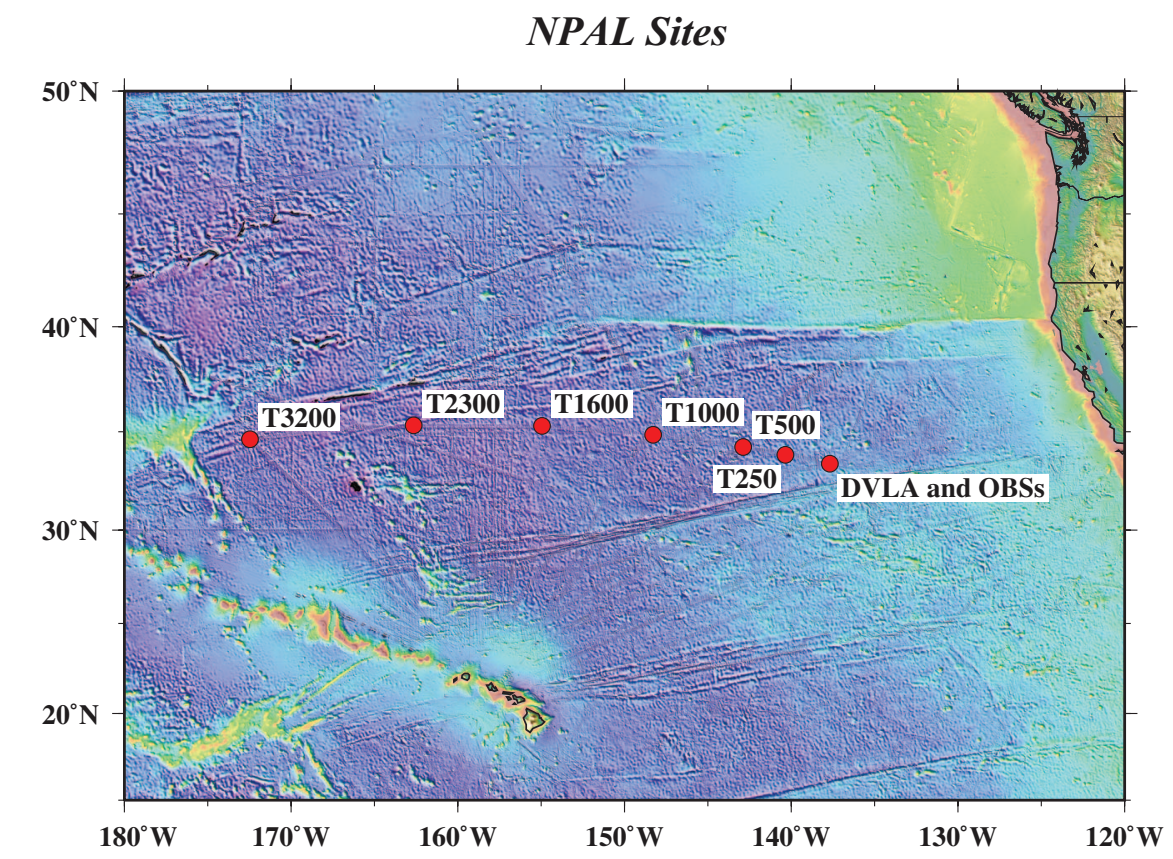

FIG. 1. The locations of the sources and receivers discussed in this paper are shown on a map of the North Pacific with the satellite-derived bathymetry (Smith and Sandwell, 1997). The geodetic lines from all of the transmission stations to the DVLA and South OBS coincide within $2 \mathrm{~km}$ (Fig. 2). The bathymetry along this geodetic line is shown as a function of longitude in the lower figure where the source and receiver longitudes are given as red dots. The bathymetry along this geodetic line is deeper than $4400 \mathrm{~m}$ everywhere.

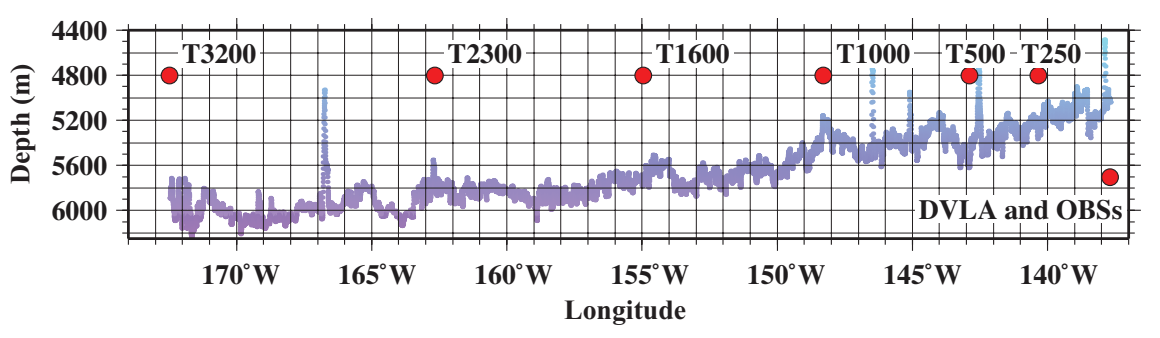

\section{B. Receivers}

In this report a preliminary comparison of the vertical component geophone data (responding to vertical particle velocity) from the south OBS/H on the seafloor (at $4973 \mathrm{~m}$ depth) with data from the deepest DVLA hydrophone (4250 m depth) (only two receiver channels from over 100 available) is presented. These are labeled OBS-S-Geo and DVLA-L20-Hyd, respectively.

\section{Processing}

Pulse-like arrivals with improved resolution $(27 \mathrm{~ms}$ in time, $40 \mathrm{~m}$ in range) and signal-to-noise ratio (SNR) were obtained by replica correlation (also called matched filtering or pulse compression, see Munk et al., 1995) applied to individual received sequences. Sequences were not summed

TABLE I. Source and receiver locations for the data presented in this paper.

\begin{tabular}{ccc}
\hline \hline & Latitude & Longitude \\
\hline DVLA-L20-Hyd & $33^{\circ} 25.1^{\prime} \mathrm{N}$ & $137^{\circ} 40.9^{\prime} \mathrm{W}$ \\
OBS-S-Geo & $33^{\circ} 23.9^{\prime} \mathrm{N}$ & $137^{\circ} 41.0^{\prime} \mathrm{W}$ \\
T250 & $33^{\circ} 52.2^{\prime} \mathrm{N}$ & $140^{\circ} 19.4^{\prime} \mathrm{W}$ \\
T500 & $34^{\circ} 14.9^{\prime} \mathrm{N}$ & $142^{\circ} 52.9^{\prime} \mathrm{W}$ \\
T1000 & $34^{\circ} 51.9^{\prime} \mathrm{N}$ & $148^{\circ} 16.8^{\prime} \mathrm{W}$ \\
T1600 & $35^{\circ} 17.1^{\prime} \mathrm{N}$ & $154^{\circ} 57.0^{\prime} \mathrm{W}$ \\
T2300 & $35^{\circ} 18.8^{\prime} \mathrm{N}$ & $162^{\circ} 38.9^{\prime} \mathrm{W}$ \\
T3200 & $34^{\circ} 37.9^{\prime} \mathrm{N}$ & $172^{\circ} 28.4^{\prime} \mathrm{W}$ \\
\hline \hline
\end{tabular}

together prior to the replica correlation. The SNR was further improved by incoherently stacking the magnitude of the replica-correlated traces. The magnitude of the traces was simply summed without regarding the phase of the complex output of the correlation process. The durations of the transmissions at each station and the number of acceptable sequences that were included in the stacked traces for OBS-SGeo and DVLA-L20-Hyd are given in Table II. A discussion of the processing, with examples, and comparisons with other analyses being carried out on the LOAPEX data set is given in Stephen et al. (2008).

\section{Bathymetry}

The locations of the sources and receivers discussed in this paper are given in Table I and are shown, overlain on

TABLE II. Approximate elapsed times and the number of acceptable sequences (NN_OBS and NN_DVLA for OBS-S-Geo and DVLA-L20-Hyd, respectively) used for the stacked traces in Figs. 4 and 5.

\begin{tabular}{cccc}
\hline \hline & $\begin{array}{c}\text { Elapsed time } \\
\text { (h) }\end{array}$ & NN_OBS & NN_DVLA \\
\hline T250 & 9 & 421 & 27 \\
T500 & 15 & 690 & 480 \\
T1000 & 34 & 1345 & 1080 \\
T1600 & 28 & 975 & 930 \\
T2300 & 14 & 606 & 576 \\
T3200 & 15 & 599 & 576 \\
\hline \hline
\end{tabular}




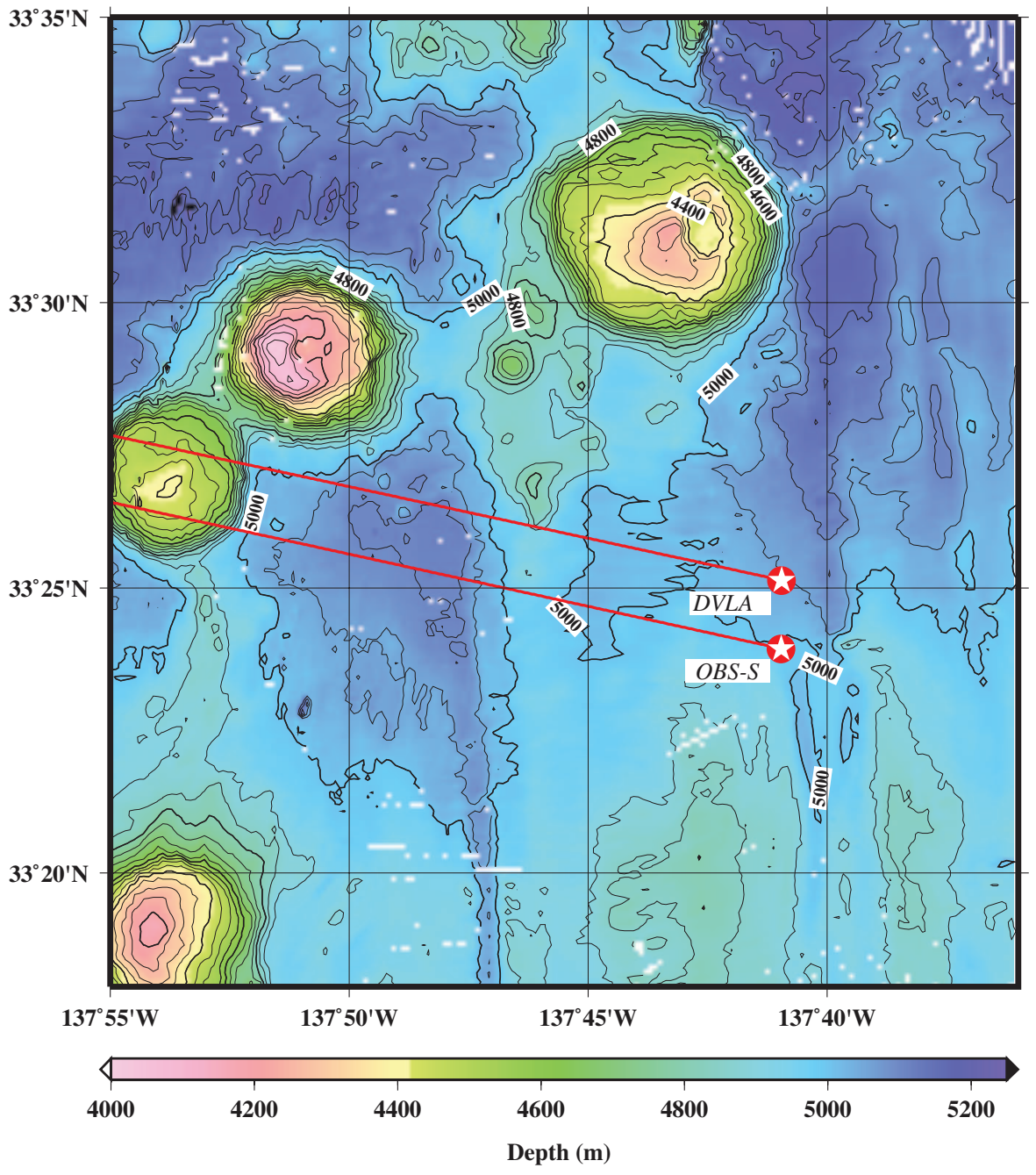

FIG. 2. The swath-mapped bathymetry within about $10 \mathrm{~nm}$ of the DVLA (Worcester, 2005) shows bottom features, as shallow as $4000 \mathrm{~m}$, that may contribute to the arrival structure discussed in this paper. The geodetic lines to the source locations are shown as red lines. The sources were positioned to lie on the same geodetic line to the DVLA. Propagation paths to the DVLA and OBS-S are coincident within $2 \mathrm{~km}$.

satellite-derived bathymetry (Smith and Sandwell, 1997), in Fig. 1. The transmitting stations were chosen so that they fall on the same geodetic line from the DVLA. The ocean depth as a function of longitude along the geodetic is given at the bottom of Fig. 1. The bathymetry is deeper than $4400 \mathrm{~m}$ everywhere along this geodetic line. There was a slight offset between the South OBS/H and the DVLA, but the geodetic lines to each are within $2 \mathrm{~km}$ (Fig. 2). Swath bathymetry was acquired during the experiments in 2004 from the DVLA out to T1000 (Worcester, 2005). At the resolution of the bathymetry in Fig. 1 there are no new features across the swath, about $2 \mathrm{~km}$ either side of the geodetic line to the DVLA.

Figure 2 shows the swath bathymetry within about $10 \mathrm{~nm}$ of the DVLA. There are four hills, all deeper than $4000 \mathrm{~m}$, that could conceivably play a role, via horizontal refraction and bottom interaction, in the arrival structure at OBS-S-Geo.

\section{E. Sound speed profiles}

Figure 3 shows the sound speed profiles based on conductivity temperature-depth (CTD) casts acquired at the transmission stations during the 2004 experiment (Mercer $e t$ al., 2005). The maximum and minimum bounds of the sound speed profiles from the World Ocean Atlas (Antonov et al., 2006; Locarnini et al., 2006), that were used for the PE modeling below, are overlain for comparison.

\section{F. Parabolic equation (PE) modeling}

To aid in the interpretation of the records, as a preliminary step, the observations are compared to PE model predictions (Collins and Westwood, 1991) based on rangedependent bathymetry from Smith and Sandwell (1997) and sound speed profiles from the 2005 World Ocean Atlas. Specifically the RAMGEO program (Collins, 1993) was used to synthesize the model records. This is a wide-angle energyconserving Padé PE propagation model. Internal waves were not included in these models. Any internal wave scattering would generate the $Z$-waves (discussed below) (Van Uffelen et al., 2009) and not the $S$-waves, so including them would not offer a likely explanation for the $S$-waves.

Initially the PE modeling consisted of two strategies. The first strategy was compressional wave modeling without bottom interaction (keep the bottom properties the same as the water above it but add strong attenuation so that no energy is returned from the seafloor or sub-seafloor). This strategy, without including bottom interaction, has successfully predicted long-range, ocean acoustic propagation in the past 


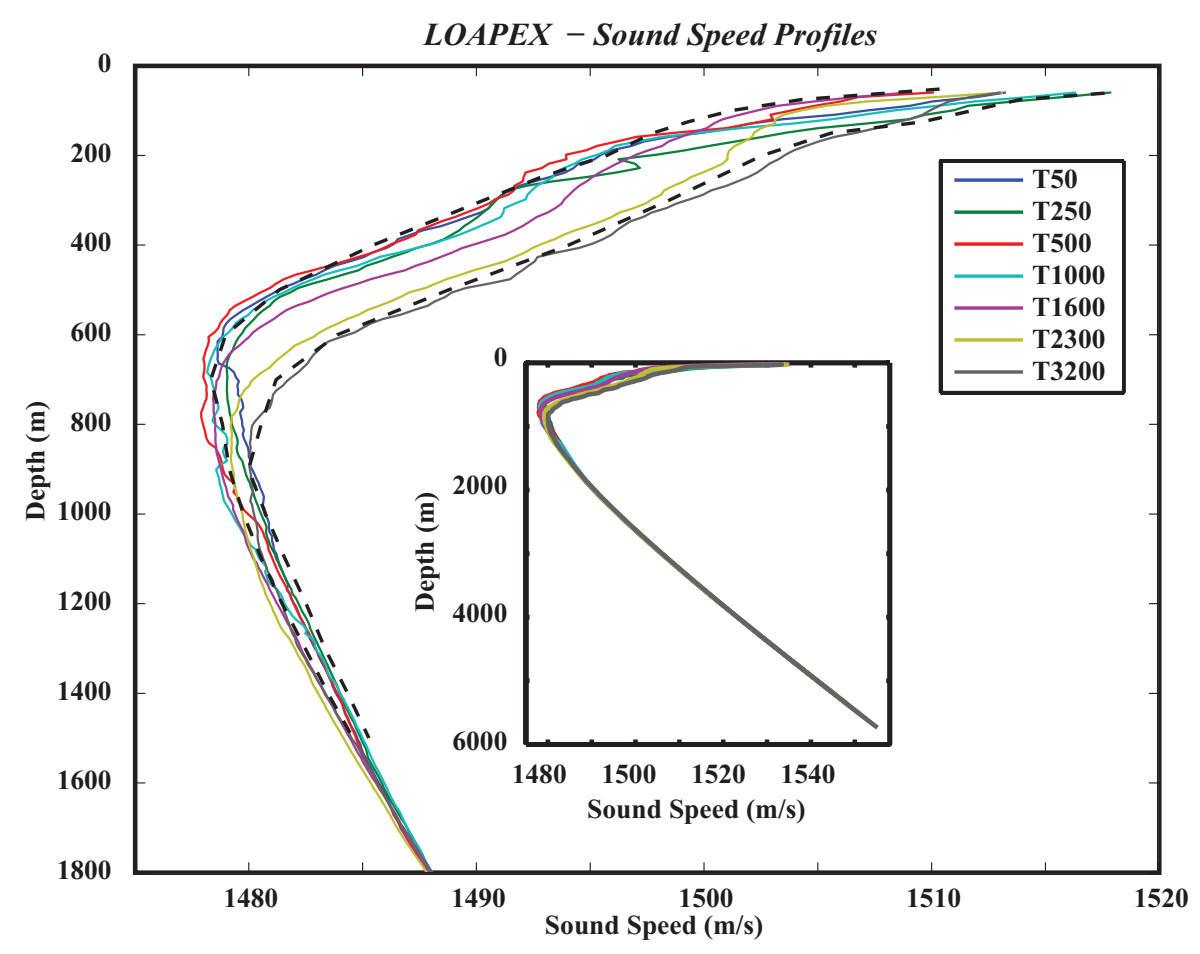

FIG. 3. The sound speed profiles that were acquired at each source location during the experiment (see Fig. 1) are shown as colored solid lines (Mercer et al., 2005). The maximum and minimum sound speeds as a function of depth from the World Ocean Atlas, that were used for the PE modeling, are shown as black, dotted lines. The profiles overlap below about $1400 \mathrm{~m}$.

using a variety of methods (Colosi et al., 2005; de GrootHedlin et al., 2009; Dushaw et al., 1999; Heaney et al., 1991; Van Uffelen et al., 2009; Wage et al., 2005; Xu, 2007). This seemed like a good initial strategy since bathymetry along the whole $3200 \mathrm{~km}$ long geodetic is everywhere deeper than $4400 \mathrm{~m}$ and for most of the propagation path is deeper than $5000 \mathrm{~m}$ (Fig. 1).

The second strategy was compressional wave modeling with bottom interaction. In this case the model is about $12 \mathrm{~km}$ thick. The seafloor consisted of (i) a $20 \mathrm{~m}$ thick layer of homogeneous sediment with $V p=1.6 \mathrm{~km} / \mathrm{s}$ and attenuation of $0.01 \mathrm{~dB} / \mathrm{m}$ at $70 \mathrm{~Hz}$ [all attenuation values are from Hamilton (1976), although better values for sediments have been recommended in more recent papers (Bowles, 1997; Kibblewhite, 1989; Mitchell and Focke, 1980)], (ii) a 2 km thick layer of basalt with a gradient in $P$-wave speed from 4.0 to $6.8 \mathrm{~km} / \mathrm{s}$ and attenuation of $0.0025 \mathrm{~dB} / \mathrm{m}$, (iii) a $4 \mathrm{~km}$ thick layer of gabbro with a gradient in $P$-wave speed from 6.8 to $8.1 \mathrm{~km} / \mathrm{s}$ and attenuation of $0.0025 \mathrm{~dB} / \mathrm{m}$, and (iv) a homogeneous half-space for the mantle at $8.1 \mathrm{~km} / \mathrm{s}$ and attenuation of $0.0025 \mathrm{~dB} / \mathrm{m}$. Density in the sediments (mostly pelagic clay) is given by: density $(\mathrm{g} / \mathrm{cc})=1.35$ $+(1.80-1.35) / 300 \times$ depth $(\mathrm{m})$ (Hamilton, 1976). For the igneous rocks density is related to compressional sound speed by: density $(\mathrm{g} / \mathrm{cc})=1.91+0.158 \mathrm{Vp}(\mathrm{km} / \mathrm{s}) \quad($ Swift et al., 1998).

Neither explicit seafloor roughness (distinct from the large-scale range-dependent bathymetry) nor shear wave properties in the bottom were included in the PE models. The point of this paper is that the arrival structure on the seafloor geophone is distinctly different from the arrival structure on a hydrophone $750 \mathrm{~m}$ above the seafloor. Future analysis will include modeling that considers the additional elastic waves (shear and interface waves) and scattering from seafloor roughness and sub-seafloor heterogeneity (Collins, 1989, 1991; Stephen and Swift, 1994; Swift and Stephen, 1994; Wetton and Brooke, 1990).

\section{ARRIVAL CLASSES}

The results of the preliminary analysis show that the arrival structure in the seafloor data has similarities and differences from the arrival structure on the DVLA. In particular, the first arrivals on the OBS/H geophone and the deepest DVLA hydrophone correspond to energy in the first deep arriving path predicted by the PE model. In addition, some of the later arrivals correspond to energy leaking from shallower turning points above the receiver; these are the socalled shadow zone arrivals previously described. Importantly, some of the later arrivals on the geophone record are not observed in the DVLA or model records. These "deep seafloor" arrivals therefore do not correspond to any previously recognized oceanic propagation path. These signals are, however, often the largest events observed on the deep seafloor at long ranges (up to $3200 \mathrm{~km}$ ).

All of the model results and data in both Figs. 4 and 5, described below, correspond to M68.2 sequence transmissions at $350 \mathrm{~m}$ depth. The data traces in both figures were computed by incoherent summing of all acceptable replicacorrelated sequences. Since the plotted traces are normalized to the maximum amplitude on the trace, the "sum" and the "average" plot the same. The number of "acceptable" sequences differed between the hydrophone and geophone channels because of different recording windows and noisy or spiky traces that were excluded from the sums. The number of "good" sequences and the total elapsed time at each station are summarized in Table II.

Some caveats of this preliminary analysis are as follows. First, all of the replica correlations presented in this paper 


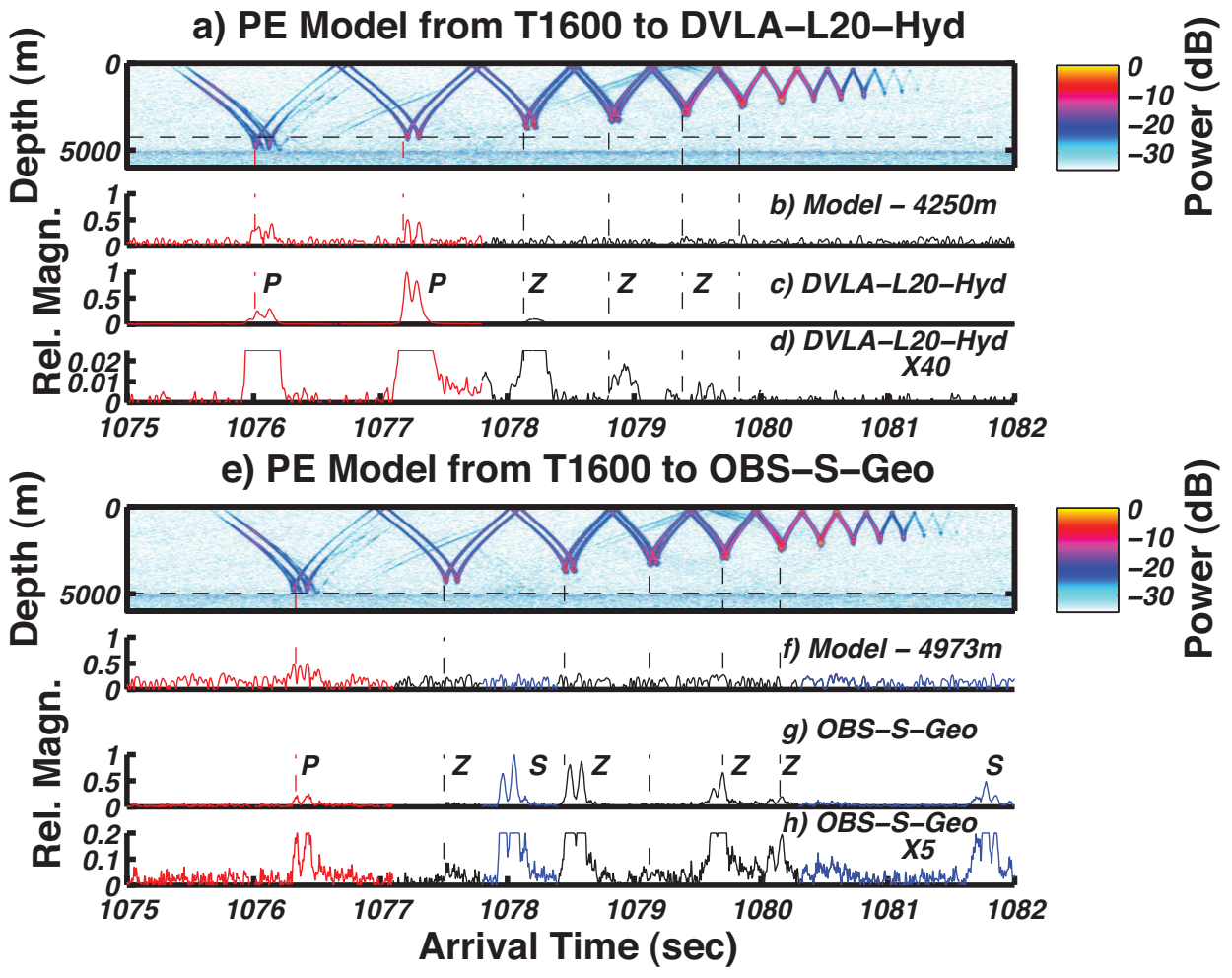

FIG. 4. This figure compares the arrival structure on DVLA-L20-Hyd and OBS-S-Geo with PE model predictions for a range of $1600 \mathrm{~km}$. The PE models include bottom interaction. The top group of four panels (a)-(d) is the model-data comparison for DVLA-L20-Hyd and the bottom group [(e)-(h)] is for OBS-S-Geo. Within each group of four, the top panel is the time front diagram, the second panel is the model trace at the receiver depth (indicated by a horizontal dashed line in the time front diagram), the third panel is the data trace normalized to its maximum amplitude, and the bottom trace is an expanded view of the data trace. Vertical dashed lines show the times of the turning points across all of the plots. Examples of the three arrival classes, "PE predicted" arrivals (P), "deep shadow zone" arrivals (Z), and "deep seafloor" arrivals (S) are indicated. The deep seafloor arrivals are an unexplained set of arrivals.

were computed assuming that the sources and receivers were stationary-no corrections for motion of the sources and receivers have been made. A preliminary analysis of Doppler effects on the data presented here (Stephen et al., 2008) indicates that this is a valid assumption. Furthermore the geophones and hydrophones on the OBS/Hs were both selfnoise limited so that only upper bounds can be placed on the true seafloor ambient noise, and the SNRs are minimum values (Stephen et al., 2006).

\section{A. DVLA-L20-Hyd arrivals}

Figure 4(a) shows the predicted time front using the PE method for an M68.2 sequence transmission at $350 \mathrm{~m}$ depth to a range of about $1600 \mathrm{~km}$ from the DVLA. This calculation includes bottom interaction. The time front between about 1080.5 and $1081.3 \mathrm{~s}$ corresponds to refracted-refracted (RR) paths, for which energy stays trapped in the sound channel and propagates over very long ranges with very little a) OBS Geophone - 4973m

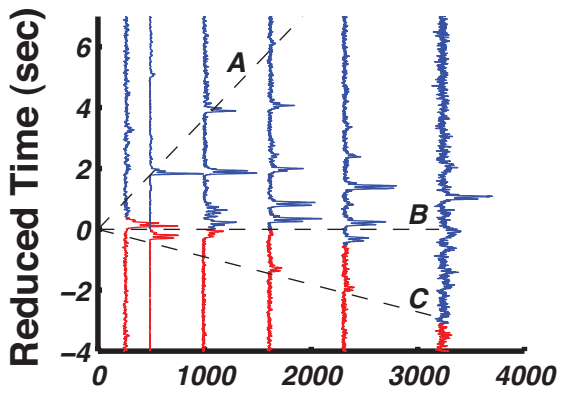

c) DVLA Hydrophone - 4250m

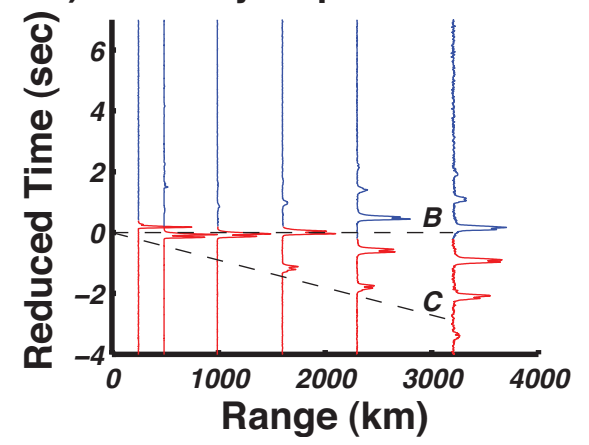

b) PE Model - 4973m

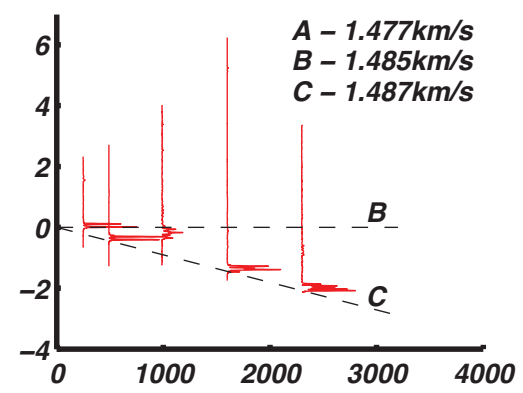

d) PE Model - 4250m

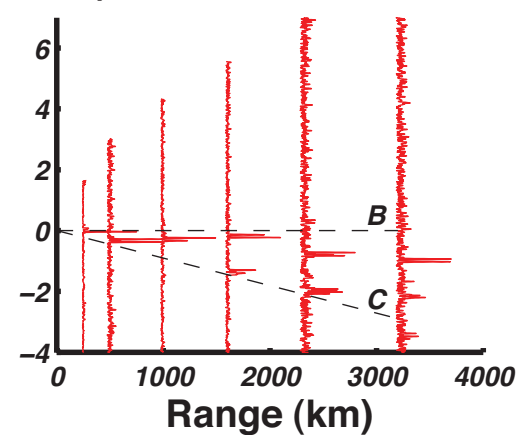

FIG. 5. The stacked traces from the OBS vertical geophone on the seafloor (a) show many more arrivals than the deepest DVLA hydrophone (c) or the PE models [(b) and (d)]. For the OBS geophone traces (a), events occurring with a sound speed faster than about $1.485 \mathrm{~km} / \mathrm{s}$ (roughly earlier than line $B)$ are predicted by the PE but there are many "late arrivals." Dashed lines correspond to three relevant speeds: (A) the apparent sound speed of the latest arrival at T500, T1000, and T1600, (B) the apparent sound speed of the largest PE arrivals at the deepest hydrophone of the DVLA which seems to separate the known early arrivals from the late unknown arrivals, and (C) the apparent sound speed of the earliest arriving energy at the OBS and DVLA, which corresponds to the deepest turning energy (see Fig. 4). The time axis has been reduced by subtracting the range divided by $1.485 \mathrm{~km} / \mathrm{s}$. 
attenuation (Munk et al., 1995). The time front from about 1075 to $1080.5 \mathrm{~s}$ corresponds to refracted surface-reflected (RSR) paths. At these frequencies there is little scattering loss on reflection from the ocean surface and energy on RSR paths also propagates to long ranges with little attenuation. (Sea states throughout the experiment were generally calm with the roughest conditions, up to sea state 3, occurring between T1600 and T2300.) The lower turning points (or caustics) of the RR and RSR paths form a progressively shallower sequence as time increases. The RSR paths (near 1076.1 and $1076.2 \mathrm{~s}$, for example) are typically brightest near the lower turning points because of focusing at the caustic. At the lower turning points, which occur above the seafloor even for the earliest arriving event, the grazing angle is zero.

Time fronts corresponding to weak surface-reflected bottom-reflected (SRBR) paths, which often attenuate very rapidly with range and are often unnecessary to successfully predict long-range, deep-water, propagation (de GrootHedlin et al., 2009; Heaney et al., 1991; Van Uffelen et al., 2009; Wage et al., 2003), can be seen as more horizontal time fronts at mid-water depths between 1076.5 and $1077.5 \mathrm{~s}$ and at shallow depths between 1078 and $1080 \mathrm{~s}$.

The arrival structure at DVLA-L20-Hyd [Figs. 4(c) and 4(d)] corresponds well with the modeled time fronts [Figs. 4(a) and 4(b)] for the earlier travel times. The first two lower turning points in the time front (at about 1076 and $1077 \mathrm{~s}$ ) reach the hydrophone depth [indicated by the horizontal dashed line in Fig. 4(a)] and clear arrivals are observed at these times. For convenience the arrivals that match the time fronts are referred to as "PE predicted" arrivals. In this example, the magnitude of the PE predicted arrivals increases with subsequent turning points.

The next two arrivals on DVLA-L20-Hyd (at about 1078 and 1078.7 s) occur at times corresponding to predicted turning points above the receiver depth. These "deep shadow zone" arrivals, which occur at about the same time as shallower turning points in the time fronts (Dushaw et al., 1999), can be attributed to diffraction and scattering by internal waves (leakage) below the turning points (Van Uffelen et al., 2009, 2006). The magnitude of the deep shadow zone arrivals decreases with subsequent turning points, as expected for decay below the progressively shallower turning point depths. There is even a weak indication of a third deep shadow zone arrival at about $1079.4 \mathrm{~s}$.

\section{B. OBS-S-Geo arrivals}

The arrival structure on OBS-S-Geo [Figs. 4(g) and 4(h)] is very different from DVLA-L20-Hyd [Figs. 4(c) and 4(d)] or the PE model. There are more arrivals and their spacing is less regular. The first, weak doublet on the geophone trace occurs below the deepest and earliest turning point in the time front. This is a PE predicted arrival.

Of the four large amplitude later arrivals, only the arrivals near 1078.4 and $1079.5 \mathrm{~s}$ appear to correspond to a turning point and could be called deep shadow zone arrivals. The large magnitude arrivals near 1078.0 and $1081.7 \mathrm{~s}$ do not correspond to turning points. These are an unexplained set of arrivals called deep seafloor arrivals. The first deep seafloor arrival, occurring near $1078.0 \mathrm{~s}$ and the largest event on OBS-S-Geo, occurs between two prominent arrivals that could be called deep shadow zone arrivals because they are beneath adjacent turning points (the weak arrival near $1077.5 \mathrm{~s}$ and the strong arrival near $1078.4 \mathrm{~s}$ ). The second deep seafloor arrival at about $1081.7 \mathrm{~s}$ is occurring after the finale time. That these arrivals are not a result of leakage from turning points of the time front is supported by the fact that these arrivals are not observed on DVLA-L20-Hyd. Further these arrivals do not correspond to the PE predicted SRBR time fronts [Figs. 4(e) and 4(f)].

The arrival at about $1078.4 \mathrm{~s}$ is the second largest event on OBS-S-Geo and it coincides with the third turning point (from the left). The arrival at about $1079.5 \mathrm{~s}$ is the third largest event on OBS-S-Geo and it coincides with the fifth turning point. These are labeled as deep shadow zone arrivals since they coincide with turning points in the PE model and there are corresponding events on DVLA-L20-Hyd (although the event below the fifth turning point is very weak). The intensity pattern on the OBS-S-Geo record is then quite curious because the deep shadow zone arrivals do not become progressively weaker as travel time increases. Deep shadow zone arrivals typically get much weaker with subsequent, shallow turning points (as on DVLA-L20-Hyd, for example). This is not the case for OBS-S-Geo and these could be deep seafloor arrivals.

\section{RECORD SECTIONS AND PROPAGATION SPEEDS}

In Fig. 5, record sections of the stacked traces for OBSS-Geo are compared to similar sections for DVLA-L20-Hyd and to predictions based on the PE model. The PE model results in Fig. 5(b) do not include bottom interaction because the results for the OBS with bottom interaction, for example, Fig. 4(f), were too noisy to show meaningful arrival structure. The PE model results for $4250 \mathrm{~m}$ depth [Fig. 5(d)] include simple bottom interaction as in Fig. 4(a). For simplicity, just the transmissions from the LOAPEX source at $350 \mathrm{~m}$ depth are considered.

A comparison of Fig. 5(a) with Fig. 5(c) readily shows that OBS-S-Geo has a very different arrival structure than DVLA-L20-Hyd at ranges from 500 to $3200 \mathrm{~km}$. Up to $2300 \mathrm{~km}$ range the first geophone arrival corresponds to the first arrival on the deepest DVLA hydrophone. Comparisons of Fig. 5(a) with Fig. 5(b) (up to $2300 \mathrm{~km}$ range) and of Fig. 5(c) with Fig. 5(d) (up to $3200 \mathrm{~km}$ range) show that the earliest arrivals on OBS-S-Geo and on DVLA-L20-Hyd are kinematically predicted by the PE model and fall on or near the propagation sound speed of $1.487 \mathrm{~km} / \mathrm{s}$, line $C$.

The late, large amplitude arrivals on OBS-S-Geo mostly occur after a slower propagation speed of $1.485 \mathrm{~km} / \mathrm{s}$ [line $B$ on Fig. 5(a)]. As discussed above and shown in Figs. 4(e)-4(h), many of these large amplitude arrivals do not correspond to turning points. Many of the events that do occur at turning point times have amplitudes that are inconsistent with purely waterborne deep shadow zone arrivals. The late arrivals on OBS-S-Geo are up to $20 \mathrm{~dB}$ larger than the earliest arrivals. 
On OBS-S-Geo [Fig. 5(a)] at 500 and $1000 \mathrm{~km}$ range, there are large amplitude arrivals occurring after the finale time and with an apparent speed of $1.477 \mathrm{~km} / \mathrm{s}$ (line $A$ ) that is slower than even the slowest sound channel minimum measured on the geodetic (about $1.478 \mathrm{~km} / \mathrm{s}$, Fig. 3). There is even a weak event at $1600 \mathrm{~km}$ range corresponding to this apparent speed. Neither of these large amplitude events is observed on the DVLA hydrophone or the PE models. These are clear examples of deep seafloor arrivals.

\section{SUMMARY}

Receptions of stacked, replica-correlated traces on a single OBS geophone on the seafloor are compared with a hydrophone moored about $750 \mathrm{~m}$ above the seafloor. The OBS geophone generally has more arrivals than the moored hydrophone. Two types of arrivals on the OBS geophone are observed that are not explained by PE modeling using simple sound speed profiles. The "deep shadow zone" arrivals occur at the time of shallower turning points (Dushaw et al., 1999; Van Uffelen et al., 2009), are consistent with decay from shallower turning points, are also observed on the DVLA hydrophones, and their arrival time is predicted by PE propagation models. The deep seafloor arrivals, on the other hand, occur later than the first PE arrival, are not readily observed on the DVLA hydrophones, and their arrival time is not predicted by PE propagation models. There are even strong arrivals after the PE predicted finale region. Deep seafloor arrivals are among the largest events observed at the seafloor. This is an unexplained set of arrivals in long-range ocean acoustic propagation.

The observed intensity pattern of the OBS arrivals is significantly more complex than the waterborne arrivals seen on the DVLA. The deep shadow zone arrivals observed on the OBS and associated with shallower turning points do not display the expected decay of intensity as travel time increases. This observation could be due to a few factors. First, the acoustic energy reaching the OBS will naturally have more bottom interaction, thus modulating the intensity pattern. Second, there could, in fact, be some interference between deep shadow zone arrivals and deep seafloor arrivals. Third, the association of some OBS arrivals with turning points may be a coincidence-all of the OBS arrivals could be deep seafloor arrivals. Fourth, in some instances the arrivals on the OBS could be associated with SRBR paths. Further analysis will be required to resolve these issues.

Deep seafloor arrivals appear to be an interface wave whose amplitude decays upward into the water column. The interface wave could be a shear-related mode coupled to the sound channel propagation (Butler, 2006; Butler and Lomnitz, 2002; Park et al., 2001) or it could be excited by secondary scattering from bottom features (Chapman and Marrett, 2006; Dougherty and Stephen, 1988; Schreiner and Dorman, 1990). These unexplained arrivals could conceivably be horizontal multi-path from some persistent ocean thermal structure, but it would be necessary to explain why they are observed on the seafloor OBS but not on the DVLA only $2 \mathrm{~km}$ away.
In this letter the existence of deep seafloor arrivals has been simply addressed and a little of their kinematics (arrival times) as observed on the geophone of one OBS has been compared with one DVLA hydrophone. In a later paper the results from the two other OBS geophones, from the OBS hydrophones, and from other hydrophones in the DVLA will be presented and discussed. The propagation physics of the arrivals will also be discussed through a quantitative analysis of signal amplitudes, ambient and system noise, and SNRs.

\section{ACKNOWLEDGMENTS}

The idea to deploy OBSs on the 2004 NPAL experiment was conceived at a workshop held at Woods Hole in March 2004 (Odom and Stephen, 2004). The LOAPEX source deployments, the moored DVLA receiver deployments, and some post-cruise data reduction and analysis were funded by the Office of Naval Research under Award Nos. N000141403-1-0181, N00014-03-1-0182, and N00014-06-1-0222. Additional post-cruise analysis support was provided to RAS through the Edward W. and Betty J. Scripps Chair for Excellence in Oceanography. The OBS/Hs used in the experiment were provided by Scripps Institution of Oceanography under the U.S. National Ocean Bottom Seismic Instrumentation Pool (SIO-OBSIP-http://www.obsip.org). To cover the costs of the OBS/H deployments funds were paid to SIOOBSIP from the National Science Foundation and from the Woods Hole Oceanographic Institution Deep Ocean Exploration Institute. The OBS/H data are archived at the IRIS (Incorporated Research Institutions for Seismology) Data Management Center.

Antonov, J. I., Locarnini, R. A., Boyer, T. P., Mishonov, A. V., and Garcia, H. E. (2006). World Ocean Atlas 2005, Vol. 2, edited by S. Levitus (U.S. Government Printing Office, Washington, DC), NOAA Atlas NESDIS 62.

Bowles, F. A. (1997). "Observations on attenuation and shear-wave velocity in fine-grained, marine sediments," J. Acoust. Soc. Am. 101, 3385-3397.

Butler, R. (2006). "Observations of polarized seismoacoustic T waves at and beneath the seafloor in the abyssal Pacific ocean," J. Acoust. Soc. Am. 120, 3599-3606.

Butler, R., and Lomnitz, C. (2002). "Coupled seismoacoustic modes on the seafloor," Geophys. Res. Lett. 29, 57-1-57-4.

Chapman, N. R., and Marrett, R. (2006). "The directionality of acoustic T-phase signals from small magnitude submarine earthquakes," J. Acoust. Soc. Am. 119, 3669-3675.

Collins, M. D. (1989). "A higher-order parabolic equation for wave propagation in an ocean overlying an elastic bottom," J. Acoust. Soc. Am. 86, 1459-1464.

Collins, M. D. (1991). "Higher-order Padé approximations for accurate and stable elastic parabolic equations with application to interface wave propagation,” J. Acoust. Soc. Am. 89, 1050-1057.

Collins, M. D. (1993). "A split-step Padé solution for the parabolic equation method," J. Acoust. Soc. Am. 93, 1736-1742.

Collins, M. D., and Westwood, E. K. (1991). "A higher-order energyconserving parabolic equation for range-dependent ocean depth, sound speed, and density," J. Acoust. Soc. Am. 89, 1068-1075.

Colosi, J. A., Baggeroer, A. B., Cornuelle, B. D., Dzieciuch, M. A., Munk, W. H., Worcester, P. F., Dushaw, B. D., Howe, B. M., Mercer, J. A., Spindel, R. C., Birdsall, T. D., Metzger, K., and Forbes, A. M. G. (2005). "Analysis of multipath acoustic field variability and coherence in the finale of broadband basin-scale transmissions in the North Pacific Ocean," J. Acoust. Soc. Am. 117, 1538-1564.

de Groot-Hedlin, C., Blackman, D. K., and Jenkins, C. S. (2009). "Effects of variability associated with the Antarctic circumpolar current on sound propagation in the ocean," Geophys. J. Int. 176, 478-490.

Dougherty, M. E., and Stephen, R. A. (1988). "Seismic energy partitioning and scattering in laterally heterogeneous ocean crust," Pure Appl. Geo- 
phys. 128, 195-229.

Dushaw, B. D., Howe, B. M., Mercer, J. A., and Spindel, R. (1999). "Multimegameter-range acoustic data obtained by bottom-mounted hydrophone arrays for measurement of ocean temperature," IEEE J. Ocean. Eng. 24, 202-214.

Hamilton, E. L. (1976). "Sound attenuation as a function of depth in the seafloor," J. Acoust. Soc. Am. 59, 528-535.

Heaney, K. D., Kuperman, W. A., and McDonald, B. E. (1991). "PerthBermuda sound propagation (1960): Adiabatic mode interpretation," J. Acoust. Soc. Am. 90, 2586-2594.

Kibblewhite, A. C. (1989). "Attenuation of sound in marine sediments: A review with emphasis on new low-frequency data," J. Acoust. Soc. Am. 86, 716-738.

Locarnini, R. A., Mishonov, A. V., Antonov, J. I., Boyer, T. P., and Garcia, H. E. (2006). World Ocean Atlas 2005, Vol. 1, edited by S. Levitus (U.S. Government Printing Office, Washington, DC), NOAA Atlas NESDIS 61.

Mercer, J., Andrew, R., Howe, B. M., and Colosi, J. (2005). "Cruise report: Long-Range Ocean Acoustic Propagation experiment (LOAPEX)," Report No. APL-UW TR 0501, Applied Physics Laboratory, University of Washington, Seattle, WA

Mercer, J. A., Colosi, J. A., Howe, B. M., Dzieciuch, M. A., Stephen, R., and Worcester, P. F. (2009). "LOAPEX: The Long-Range Ocean Acoustic Propagation Experiment," IEEE J. Ocean. Eng. 34, 1-11.

Mercer, J. A., Howe, B. M., Andrew, R. K., Wolfson, M. A., Worcester, P. F., Dzieciuch, M. A., and Colosi, J. A. (2006). "The Long-Range Ocean Acoustic Propagation Experiment (LOAPEX): An overview," J. Acoust. Soc. Am. 120, 3020.

Mitchell, S. K., and Focke, K. C. (1980). "New measurements of compressional wave attenuation in deep ocean sediments," J. Acoust. Soc. Am. 67, 1582-1589

Munk, W., Worcester, P., and Wunsch, C. (1995). Ocean Acoustic Tomography (Cambridge University Press, Cambridge, UK).

Odom, R. I., and Stephen, R. A. (2004). Proceedings, Seismo-Acoustic Applications in Marine Geology and Geophysics Workshop, Woods Hole Oceanographic Institution, [Report No. APL-UW TR 0406, Applied Physics Laboratory, University of Washington, Seattle, WA].

Park, M., Odom, R. I., and Soukup, D. J. (2001). "Modal scattering: A key to understanding oceanic T-phases," Geophys. Res. Lett. 28, 3401-3404.

Schreiner, M. A., and Dorman, L. M. (1990). "Coherence lengths of seafloor noise: Effect of ocean bottom structure,” J. Acoust. Soc. Am. 88, 1503 1514.

Smith, W. H. F., and Sandwell, D. T. (1997). "Global seafloor topography from satellite altimetry and ship depth soundings," Science 277, 19561962.

Stephen, R. A., and Swift, S. A. (1994). "Modeling seafloor geoacoustic interaction with a numerical scattering chamber," J. Acoust. Soc. Am. 96, 973-990.

Stephen, R. A., Mercer, J. A., Andrew, R. K., and Colosi, J. A. (2006). "Seafloor hydrophone and vertical geophone observations during the North Pacific Acoustic Laboratory/Long-range Ocean Acoustic Propagation Experiment (NPAL/LOAPEX),”J. Acoust. Soc. Am. 120, 3021.

Stephen, R. A., Bolmer, S. T., Udovydchenkov, I., Worcester, P. F., Dzieciuch, M. A., Van Uffelen, L., Mercer, J. A., Andrew, R. K., Buck, L. J., Colosi, J. A., and Howe, B. M. (2008). "NPAL04 OBS data analysis part 1: Kinematics of deep seafloor arrivals," Report No. WHOI-2008-03, Woods Hole Oceanographic Institution, Woods Hole, MA.

Swift, S. A., and Stephen, R. A. (1994). "The scattering of a low-angle pulse beam by seafloor volume heterogeneities," J. Acoust. Soc. Am. 96, 9911001 .

Swift, S. A., Lizarralde, D., Hoskins, H., and Stephen, R. A. (1998). "Seismic attenuation in upper oceanic crust at Hole 504B," J. Geophys. Res. 103, 27193-27206.

Van Uffelen, L., Worcester, P., and Dzieciuch, M. (2008). "Absolute intensities of acoustic shadow zone arrivals," J. Acoust. Soc. Am. 123, 3464.

Van Uffelen, L. J., Worcester, P. F., Dzieciuch, M. A., and Rudnick, D. L. (2009). "The vertical structure of shadow-zone arrivals at long range in the ocean," J. Acoust. Soc. Am. 125, 3539-3588.

Van Uffelen, L. J., Worcester, P. F., Dzieciuch, M. A., Rudnick, D. L., Cornuelle, B. D., and Munk, W. H. (2006). "The vertical structure of shadow-zone arrivals at long range in the ocean (A)," J. Acoust. Soc. Am. 119, 3344.

Wage, K. E., Baggeroer, A. B., and Preisig, J. C. (2003). "Modal analysis of broadband acoustic receptions at $3515-\mathrm{km}$ range in the North Pacific using short-time Fourier techniques," J. Acoust. Soc. Am. 113, 801-817.

Wage, K. E., Dzieciuch, M. A., Worcester, P. F., Howe, B. M., and Mercer, J. A. (2005). "Mode coherence at megameter ranges in the North Pacific Ocean," J. Acoust. Soc. Am. 117, 1565-1581.

Wetton, B. T. R., and Brooke, G. H. (1990). "One-way wave equations for seismoacoustic propagation in elastic waveguides," J. Acoust. Soc. Am. 87, 624-632.

Worcester, P. (2005). "North Pacific Acoustic Laboratory: SPICE04 Recovery Cruise Report," Scripps Institution of Oceanography, La Jolla, CA.

$\mathrm{Xu}$, J. (2007). "Effects of internal waves on low frequency, long range, acoustic propagation in the deep ocean," Ph.D. thesis, MIT/WHOI Joint Program, Woods Hole, MA. 